\title{
Best Practices Nursing Guideline in Phlebotomy for Patient Safety and Quality Improvement
}

\author{
${ }^{1}$ Heba Abdel Mowla Ahmed, ${ }^{2}$ Lobna Mohamed Gamal Ali \\ ${ }^{1}$ Lecturer of Medical Surgical Nursing Department, Faculty of Nursing, University of Alexandria, Egypt. \\ ${ }^{2}$ Lecturer of Medical Surgical Nursing Department, Faculty of Nursing, El-Minia University, Egypt.
}

\begin{abstract}
Phlebotomy has practiced for centuries and still one of the most common invasive procedures in health care settings. Each step in this procedure affects the quality of the specimen and is thus important for preventing laboratory errors 0 , patient injury and even death. Unfortunately, phlebotomy poses risks for nurses and still common to carry out dangerous of practices known to increase the risk of needle-stick injury and transmission of blood borne diseases. The touch of a finger to verify the location of a vein before insertion of the needle increases the chance that a specimen may contaminated. This can cause false blood culture results, prolong hospitalization, delay diagnosis and cause unnecessary use of antibiotics. Clinical nursing errors in completing forms and identifying patients are common, costly and preventable. Other adverse effects for patients are common; they include bruising at the site of puncture, fainting, nerve damage and haematomas. The aim of the study was to investigate the effect of developed best practices nursing guideline in phlebotomy on patients' safety and quality improvement. The research hypothesis, implement the developed best practices nursing guideline for phlebotomy will improve the patient safety and quality improvement. Method: A quasiexperimental design utilized in this study. A convenient sample of 80 patients divided equally into study and control groups, 40 patients each. The study conducted at all inpatient medical departments of the Main University Hospital at Alexandria, Egypt. Data was collected using Phlebotomy Nurses' Performance Observational Checklist consists of three parts. Results showed that there was high incidence of phlebotomy local complications among the control group patients. From the investigators observations, this result may be due to lacking of nursing skills related to different aspects of phlebotomy. In addition, it may be due to inadequate basic education, unavailability of orientation and in-service training programs as well as postgraduate courses. In conclusion, applying the best practices nursing designed guideline for patient safety and quality improvement was effective in phlebotomy.Illustrated best practices nursing guideline should be available as a reference for health care settings recommended [Heba Abdel Mowla Ahmed, ${ }^{2}$ Lobna Mohamed Gamal Ali. Best Nursing Practices in Phlebotomy Patient Safety and Quality Improvement].
\end{abstract}

Keywords: Patient Safety, Quality Improvement, Phlebotomy, Nursing Practices, Phlebotomy

\section{Introduction}

Phlebotomy has practiced for centuries and is still one of the most common invasive procedures in health care. However, practice varies considerably between countries, and between institutions and individuals within the same country ${ }^{(1)}$. By its nature, phlebotomy has the potential to expose nurses and patients to blood from other people, putting them at risk from bloodborne pathogens. These pathogens include human immunodeficiency virus (HIV), hepatitis B virus (HBV), hepatitis C virus (HCV), and those causing viral hemorrhagic fevers ${ }^{(2)}$.

If a blood sample is poorly collected, the results may be inaccurate and misleading to the clinician, and the patient may have to undergo the inconvenience of repeat testing. The three major issues resulting from errors in collection are haemolysis, contamination and inaccurate labelling ${ }^{(3)}$. Factors that increase the risk of hemolysis include use of a needle of too small a gauge 23 or under, or too large a gauge for the vessel; pressing. The syringe plunger to force the blood into a tube, thus increasing the shear force on the red blood cells; drawing blood specimens from an intravenous or central line. On the other hand under filling a tube so that the ratio of anticoagulant to blood is greater than 1:9; reusing tubes that have refilled by hand with inappropriate amounts of anticoagulants; mixing a tube too vigorously. Also, failing to let alcohol or disinfectant dry; using too great a vacuum; for example, using too large a tube for a paediatric patient, or using too large a syringe (10$20 \mathrm{ml})^{(4)}$.

Serious adverse events linked with phlebotomy are rare, but may include loss of consciousness with tonic clonic seizures. Less severe events include pain at the site of venipuncture, anxiety and fainting ${ }^{(5)}$. The best-documented adverse events are in blood transfusion services, where poor venepuncture practice or anatomical abnormality has resulted in bruising, haematoma and injury to anatomical structures near the needle entry ${ }^{(6)}$. 
Injuries from sharps (i.e. items such as needles that have corners, edges or projections capable of cutting or piercing the skin) commonly occur between the use and disposal of a needle or similar device ${ }^{(7)}$. One way to reduce accidental injury and blood exposure among nurses is to replace devices with safety (i.e. engineered) devices. Reporting of accidental exposure to blood and body fluids is more frequent from wellestablished health-care systems; however, it thought that the incidence of such exposures is actually higher in systems that are not so well equipped ${ }^{(8)}$.

To reduce the risk of adverse effects for patients, nurses undertaking phlebotomy need to trained in procedures specific to the types of specimen they collect ${ }^{(9)}$. Such procedures may include arterial sampling, capillary sampling, blood culture collection and venous blood draws. Nurses who collect specimens from children and infants will need special training and practice for these procedures ${ }^{(10)}$.

When taking blood, nurses should wear well-fitting, non-sterile gloves, and should carry out hand hygiene before and after each patient procedure, before putting on gloves and after removing them. The blood should take in a dedicated location that ensures patient comfort and privacy ${ }^{(11)}$. To remove the risk of environmental contamination with pathogens, counter and work surfaces, and chair arms should clean with disinfectant at the start of each shift and when visibly dirty ${ }^{(12)}$. To prevent infections and other adverse events, nurses should follow the guidelines on patient identification, hand hygiene, use of gloves, skin disinfection, and use of appropriate blood-sampling devices and safe transportation of laboratory samples. Patient consent and cooperation are important components of respecting patient rights. A patient information leaflet or poster that explains the procedure in simple terms is helpful ${ }^{(13)}$.

Best practices in phlebotomy protect nurses as well as patients. One way to reduce accidental injury and blood exposure among nurses is to use safety (i.e. engineered) devices such as retractable lancets, syringes with needle covers or retractable needles and, when appropriate, plastic laboratory tubes ${ }^{(14)}$. Another approach is to eliminate two-handed needle recapping and manual device disassembly, and instead dispose of the sharps into a puncture- resistant sharps container (i.e. a safety container) immediately after use ${ }^{(15)}$. . The best practice is to discard the needle and syringe, or needle and tube holder, as a single unit, into a sharps container that is clearly visible and within arms reach. The size of the container should permit disposal of the entire device rather than just the needle ${ }^{(16)}$.

Being well prepared, having all materials available, and working in a suitable environment increases fluency ${ }^{(17)}$. Integration means adapting the practical skill to the patient and the situation by harmonising parallel aspects of the skill, such as performance, physical support, and verbal interaction, that is, being attentive to the total needs of the patient. Caring comportment means creating an atmosphere that is respectful, accepting and encouraging. It also includes personnel taking the patient's feelings into account, as well as the patient's reaction to the instrumental steps of the practice ${ }^{(18)}$.

Patient safety and prevention of errors. Two international descriptions of patient safety are "the reduction of risk of unnecessary harm associated with healthcare to an acceptable minimum" and "prevention of errors and adverse effects to patients associated with health care ${ }^{(19)}$. A Swedish definition is "protection from healthcare related injury" (41). Since the late 20th century, intensive efforts to identify avoidable injuries in healthcare have been made both internationally and nationally ${ }^{(20)}$. Still, after all these efforts with the purpose to improve healthcare, no major changes seen globally.

Prevention of complications is an important goal of good nursing care. A general way to eliminate errors has been to report adverse events and thereafter try to learn from them ${ }^{(21)}$. Underreported adverse events range between 50\% and $96 \%$ annually ${ }^{(22)}$. Therefore, assessment of near misses that can lead to adverse events and occur more often than adverse events may add noticeably more value to healthcare improvement than sole focus on adverse events ${ }^{(23)}$. Intervening healthcare personnel acting as the last line of defense may be able to prevent injuries.

Phobia about phlebotomy is common and estimated to occur in up to $3.5 \%-4 \%$ of all collections. Phobia is anxiety caused by a previous bad experience in a specific situation, often leading to avoidance behavior ${ }^{(24)}$. Phlebotomy considered as something phlebotomy personnel just do, and patients not always asked for consent. Patient consent is essential for all healthcare procedures, including phlebotomy. Asking for consent and giving information about the procedure, or analysis should do and can reduce patient anxiety ${ }^{(25)}$. Nurses should never underestimate the impact on the patient undergoing phlebotomy. Correct phlebotomy practices reduce anxiety and pain for patients undergoing phlebotomy and lead to reliable test results ${ }^{(26)}$.

Patient preparation procedures: Patients need to be correctly prepared before phlebotomy requisitioned analyses. For example, fasting and patient rest are common preparation procedures ${ }^{(27)}$. Only $6 \%$ of phlebotomy personnel in PHCs reported that they always allowed the patient to rest at least 15 minutes in a sitting position before phlebotomy, compared to $18 \%$ of hospital phlebotomy personnel. That the patient should rest in a sitting position for 15 minutes prior to sampling recommended, because changes of body position affect the plasma volume ${ }^{(28)}$. Changes in plasma volume might influence the test results for some analyses, for example, albumin, aldosterone, LDL, and HDL cholesterol, which increase by 5\%-15\%. Test results compared with previous 
results or reference intervals. Therefore, sampling following the same procedures is important to ensure reliable and comparable test results. Reliable test results lead to less repeated sampling and minimizes patient suffering (29)

Identification procedures in this thesis, identification procedures include patient identification procedures, labelling of test tubes, and test request management ${ }^{(30)}$. During a 6- month period, 352 samples per million were found to have identification errors in an Italian hospital. They constituted approximately $27 \%$ of all pre-analytical errors and included failure to check the patient's identity and failure to include the patient's name in the request. Similar figures reported in other studies ${ }^{(31)}$. . All identification errors have similar consequences; as the errors may result in delayed or missed diagnosis, mix up of patients, wrong treatment, or even death ${ }^{(32)}$.

An adverse event estimated to occur in one of every 18 identification errors. Identification procedures have improved in recent years due to computerized systems ${ }^{(33)}$. Computer systems have reduced errors in name, identification number, and care unit on the test request, but have not eliminated the risk of mismatching patients during phlebotomy. An international recommendation is to have two identifiers when collecting blood samples for clinical testing ${ }^{(34)}$.

Labelling of test tubes: Mislabeling is common, and accounts for about 50\%-65\% of all identification problems. One study estimated mislabeling of test tubes at one error in every 165 specimens ${ }^{(35)}$. In Sweden in 2009, the National Board of Health and Welfare reported 40 adverse events during blood transfusion; 20 of these adverse events were due to incorrect labelling of test tubes ${ }^{(36)}$. In hospitals, $22 \%$ of phlebotomy personnel reported labelling the test tube at a later occasion away from the patient. Labelling errors may be latent. There is no direct interaction between the patient and the healthcare professionals who interpret and report the test results (37). In Sweden, test tubes should always labelled prior to blood collection, but guidelines are contradictory, and some recommend labelling in close proximity to the patient. Other suggestions to decrease labelling errors are barcoded wristbands and new handheld computer resources for both patient and sample ${ }^{(38)}$.

Test request errors have found in several studies, and estimated to range between $4 \%$ and $8 \%$ of all errors in the total testing process. As many as $10 \%-25 \%$ of phlebotomy personnel have reported not always signing the test request. As well, paper-based test requests are an important source of errors in the Pre-analytical phase ${ }^{(39)}$. The information on test requests should compared and rechecked with the patient's full name and identification number to ensure patient safety.

Venipuncture problems in the pre-analytical phase are often associated with venipuncture (phlebotomy), for example, empty filled tubes, wrong type of collection tube, and incorrect use of venous stasis ${ }^{(40)}$. Venous stasis used to make the veins more visible and easier to localize and puncture. Venous blood specimen handling, multiple factors are associated with incorrect handling of blood specimens. In addition, collection tube centrifugation delays, missing tubes. As well as clotting, incorrect inversion, and incorrect storage of samples occur ${ }^{(41)}$.

Significance of the study: The fact that about $60 \%-80 \%$ of decisions regarding diagnosis and treatment are based on laboratory test results. Low adherence to phlebotomy guidelines may lead to erroneous or delayed test results, causing patient harm and high healthcare costs.

As patient safety considered a priority in all modern healthcare and it essential during nursing care. Avoiding patient injury and providing the best possible care is a continuous struggle. Laboratory results following phlebotomy constitute a major cornerstone in the diagnosis and treatment of patients. Phlebotomy errors may cause delay in diagnosis, repeated sampling, and erroneous treatment. These errors jeopardise patients' health and safety. The general practice of phlebotomy described in local and national guidelines that should followed by healthcare personnel.

The literature review and our earlier studies show that low adherence to phlebotomy guideline practices is common and can cause serious errors such as incorrect identification procedures, incorrect specimen collection practices, and incorrect handling of specimens. In addition, there is a lack of implementation advice in phlebotomy guidelines, as well as a lack of continuous personnel education aiming to update and sustain proper phlebotomy practices.

Aim of the Study:

The aim of the study was to investigate the effect of developed best practices nursing guideline in phlebotomy on patient safety and quality improvement.

\section{Research Hypothesis:}

Implement the developed best practices nursing guideline in phlebotomy will improve patient safety and quality improvement.

Subjects and Method:

Design: The present research design was quasi experimental.

Setting: The present study conducted at inpatient medical departments of the Main University Hospital at Alexandria, Egypt. 
Subjects: A convenient sample of 80 adult patients was included in the study. Patients selected from the abovementioned settings and divided equally into study and control groups, 40 patients each. The selection of the subjects of the study done according to the following criteria:

1- Age group from 20 to 60 years old.

2- They had normal blood count.

3-They had no evidence of metabolic decompensation such as; diabetes mellitus, congestive heart failure, hypertension, renal diseases and/or any form of homeostatic blood disorders.

4-Patients who were immunocompromised, receiving chemotherapy or anticoagulant drugs excluded from the sample.

Tool: Observation Checklist (instead of Patient's Phlebotomy Local Complications Assessment Sheet). The investigators based on review of relevant literature developed this tool. It mainly aimed to address the parameters related to clinical criteria of phlebotomy local complications In addition, to evaluate the pain over or near the phlebotomy site ${ }^{(42,43,44,45)}$. It was comprised of three parts:

Part I. Address biosociodemographic and medical data that included items related to; patient's name, age, sex, level of education. In addition, occupation, department, residence, date of admission, telephone number, activity level, date of being involved in the study, hospital number. On the other hand, medical diagnosis, history of skin allergy to alcohol, betadine and/or adhesive tape, medical history of mastectomy, arterio-venous shunt, neurovascular injury, cellulitis, thrombosis and/or thrombophlebitis, history of oral anticoagulant or platelet inhibitors on admission. As well as, recent laboratory findings as well as vital signs, blood pressure before phlebotomy and the body temperature.

Part II. Determine the clinical signs and symptoms of local complications caused by phlebotomy using: a- Phlebitis Scale: Masoorli (1996) developed it ${ }^{(46)}$, to assess the occurrence of phlebitis. It is standardized scale from (0 to 3 ) corresponding to clinical signs of phlebitis, where (0) indicates no symptoms, (1) indicates erythema with or without pain, (2) indicates streak formation with no palpable cord, while (3) indicates streak formation with palpable cord.

b-Other local phlebotomy complications: Such as thrombophlebitis, ecchymosis and hematoma, infection and venous spasm over or near the site of the phlebotomy. Each complication identified through certain signs and symptoms. Suitable scoring system used. A score of (2) points was given to present and measurable clinical signs and symptoms, (1) point for present but not measurable clinical signs and symptoms, while (0) was given for absent clinical signs and symptoms. Clear elastic millimeter ruler used to measure the degree of these local complications. In addition, a column left for any observation ${ }^{(47)}$.

Part III. Assess the subjective level of pain severity and patient's description of pain over or near the phlebotomy site:

A- Visual Analogue Scale: It was developed by Melzac and Katz $(1994)^{(48,49)}$ and it aimed to assess the subjective level of pain severity over or near the phlebotomy site. It is a standardized linear scale from (Zero to ten) corresponding to the degree of pain, where zero indicates no pain and ten indicates the worst pain. In addition, one up to three indicates mild pain, while (three up to six) indicates moderate pain; finally (six up to ten) indicates severe pain.

B- Pain description: It aimed to assess patient's description of pain over or near the phlebotomy site. It includes forms of pain description that are stabbing, sharp, nagging, dull, burning, throbbing and boring pain".

\section{Methods}

1. An official permission obtained from the hospital administrators of nursing service department after explanation of the aim of the study.

2. The Patient's Phlebotomy Complications Assessment Sheet developed by the investigators after review of relevant literature. It submitted to a jury composed of nine experts in the field of adult nursing of the Faculty of Nursing, and four experts in the field of anesthesia of the Faculty of Medicine, both at Alexandria University to test content validity. Comments and suggestions of the jury reviewed and the necessary modifications done as indicated, thereafter.

3. Patient's consent for participation in the study obtained if he or she met the subject selection criteria, and was willing to participate in the study after explanation of the aim of the study and anonymity assured.

4. Phlebitis and other local phlebotomy complications scales had been tested for their applicability by Helmy $(1981)^{(50)}$ and Abdel Wahab (1994) ${ }^{(51)}$. Visual Analogue Scale have been tested for its applicability by Aly $(2003)^{(52)}$ and Sofar $(2006)^{(53)}$.

5. A pilot study conducted by the investigators on five patients. These patients excluded from the study sample. The purpose of the pilot study was to check and ensure the clarity, feasibility and applicability of the study tool.

6. Patients assigned randomly into either the control or the study group. The investigators started with 
observations of the control group then the intervention and observations for the study group done in order to prevent sample contamination.

7. Data collected from patients through interview and continuous observation methods. Data collections lasted about four months. It started on the beginning of (January 2015 until the end of May 2015).

8. The control group was receiving the phlebotomy routine hospital care. Patients of the study group were receiving phlebotomy-nursing intervention by the investigators before, during and after the phlebotomy.

9. Nursing intervention done by the investigators with assistance of professional nurse at evening and night shifts. The assistant professional nurse received training from the investigators on the phlebotomy care. The illustrated manual for phlebotomy best practices nursing guideline (54, 55, 56, 57) developed by the investigators, and consisted of two parts; part (1) procedure manual and part (2) performance check list. It submitted to a jury composed of nine experts in the field of adult nursing of the Faculty of Nursing, and four experts in the field of anesthesia of the Faculty of Medicine, both at Alexandria University to test content validity. Comments and suggestions of the jury reviewed and the necessary modifications done as indicated.

\section{A- Before Phlebotomy:}

a) Physician written order for blood sample collection checked.

b) Hands washed (before and after phlebotomy site palpation, inserting or dressing the phlebotomy site).

c) Patients were prepared psychologically and physically for phlebotomy.

d) The environment was prepared and checked for cleanliness, ventilation, adequate lighting, visitors were excluded as well as windows and doors were closed.

e) The patients and/or their families were received a brief explanation about the patient's position, phlebotomy procedure, then verbal consent was obtained.

f) Patients' assessed before the phlebotomy for history of skin allergy to alcohol, betadine and /or adhesive tape. Medical history taken for mastectomy, arterio-venous shunt, neurovascular injury, cellulitis, thrombosis and /or thrombophlebitis. In addition, history of prescribed medications such as, oral anticoagulant and/or platelet inhibitors taken.

g) The phlebotomy site selected based on Mapping out a Plan. The phlebotomy site assessed to evaluate the presence of local complications using observation and palpation techniques. The vein that selected for phlebotomy assessed for refilling time using Small Vein Refill Test, normally three seconds to refill has taken.

h) The needed equipment assembled to the bedside.

i) The phlebotomy site was prepared through:

a. Techniques used for vein dilatation, which were maintained by applying warm towel for (5 to10) minutes followed by placing the blood pressure cuff around the patient's arm and inflate it to the point between the systolic and diastolic of patient's blood pressure approximately $100 \mathrm{mmHg}$.

b. The skin disinfected with alcohol $70 \%$ followed by betadine $10 \%$. The antiseptic solution was allowed to remain on the insertion site for (1 to 3 ) minutes before phlebotomy for maximum effective action.

\section{B- During the Phlebotomy:}

a) Strict aseptic technique followed.

b) Barrier precautions during phlebotomy and care followed through non-latex or latex gloves were weared during the phlebotomy and changing the dressings of the phlebotomy site.

c) The needle bevel directed up during the phlebotomy when the vein diameter was larger than the used needle shaft diameter, while it directed down when the used needle shaft diameter was larger than the vein diameter.

d) Phlebotomy technique was standardized two hands technique using 15 to 30 degrees angle.

C- After the Phlebotomy:

a) The used supplies were disposed.

b) Phlebotomy site dressing was applied

c) The phlebotomy site assessed and evaluated at least every shift from (2 to 4) hours for evidence of phlebotomy related complications. This done through gentle palpation of the puncture site through the intact dressing.

10- Specially designed observational checklist sheet developed by the investigators in order to evaluate the nurses' performance related to phlebotomy and suitable scoring system was developed. 
11-The clinical signs and symptoms of phlebotomy complications were determined for both study and control groups using Phlebotomy Local Complications Assessment Sheet.

12- Assessment of subjective level of patients' pain and patient's description of pain over or near the phlebotomy site measured using Visual Analogue Scale and descriptions of pain during the phlebotomy, immediate after the puncture and as sign associated with phlebotomy complications if present.

13- Evaluation of the effect of nursing intervention on the condition of the patients through using Patient's Phlebotomy Local Complications Assessment Sheet related to clinical parameters and criteria of phlebotomy complications done for both groups.

14- Comparisons of phlebotomy complications regarding every single observation between control and study groups done.

\section{5- Statistical Analysis:}

The Data collected and entered into the personal computer. Statistical analysis done using Statistical Package for Social Sciences (SPSS version 20) software. Both descriptive and inferential statistic established. Chi square test used. The level of significant was considered at $\mathrm{P}$ - value $<0.05$.

\section{Ethical Considerations:}

The Ethical Committee of the faculty of nursing approved the research. An official permission and official letter was obtained from the administrator of the pre-mentioned settings to get the permission for

\section{Results}

This study done in order to evaluate the effect of specific nursing interventions on the occurrence of phlebotomy local complications in order to improve the quality and patients' safety.

Table 1: Illustrates the characteristics of the control and the study groups according to their age, gender, level of activity and the educational level. It was observed that the majority of total patients $(38.75 \%)$ were in the age $(50 \leq$ 60 years), while about $(10.00 \%)$ were in the age $(20<30$ years). As Regards patient's gender, it noticed that female patients represented slightly higher percentage $(51.25 \%)$ than male patients $(48.75 \%)$ did. In relation to activity level, it seen that more than half of the patients $(66.25 \%)$ were active. However, $(6.25 \%)$ were bed ridden. As regards the educational level $(50.00 \%)$ of the patients have primary education, while $(2.50 \%)$ have secondary education.

Table 1: The Characteristics of the Control and the Study Groups According to Their Age, Gender, Level of Activity and the Educational Level.

Regarding post phlebotomy local complications, it noticed that the highest percentages of incidence of the local complications affected the control group. Ecchymosis and hematoma, thrombosis, venous spasm and needle dislodgment which were $(35.00 \%, 25.00 \%, 20.00$ and $12.20 \%)$ respectively and only $(7.50 \%)$ were suffering from post-phlebotomy local infection while in the study group all patients were free from any local complications in the phlebotomy site $(0.00 \%)$.

\begin{tabular}{|c|c|c|c|c|c|c|}
\hline \multirow{2}{*}{$\begin{array}{l}\text { Patients' } \\
\text { Characteristics }\end{array}$} & \multicolumn{2}{|c|}{$\begin{array}{l}\text { Control Group } \\
n=40\end{array}$} & \multicolumn{2}{|c|}{$\begin{array}{l}\text { Study Group } \\
\mathrm{n}=\mathbf{4 0}\end{array}$} & \multicolumn{2}{|c|}{$\begin{array}{l}\text { Total } \\
\mathrm{n}=\mathbf{8 0}\end{array}$} \\
\hline & NO. & $\%$ & NO. & $\%$ & NO. & $\%$ \\
\hline \multicolumn{7}{|l|}{ - Age in years: } \\
\hline$-20<30$ & 6 & 15.00 & 2 & 5.00 & 8 & 10.00 \\
\hline$-30<40$ & 7 & 17.50 & 6 & 15.00 & 13 & 16.25 \\
\hline$-40<50$ & 14 & 35.00 & 14 & 35.00 & 28 & 35.00 \\
\hline$-50 \leq 60$ & 13 & 32.50 & 18 & 45.00 & 31 & 38.75 \\
\hline \multicolumn{7}{|l|}{ - Gender: } \\
\hline - Male & 19 & 47.50 & 20 & 50.00 & 39 & 48.75 \\
\hline - Female & 21 & 52.50 & 20 & 50.00 & 41 & 51.25 \\
\hline \multicolumn{7}{|l|}{ - Activity Level: } \\
\hline - Active & 26 & 65.00 & 27 & 67.50 & 53 & 66.25 \\
\hline $\begin{array}{l}\text { - Active with } \\
\text { assistance }\end{array}$ & 10 & 25.00 & 12 & 30.00 & 22 & 27.50 \\
\hline - Bed ridden & 4 & 10.00 & 1 & 2.50 & 5 & 6.25 \\
\hline \multicolumn{7}{|c|}{ - Educational Level: } \\
\hline - Illiterate & 15 & 37.50 & 15 & 37.50 & 30 & 37.50 \\
\hline - Primary & 20 & 50.00 & 20 & 50.00 & 40 & 50.00 \\
\hline - Preparatory & 4 & 10.00 & 4 & 10.00 & 8 & 10.00 \\
\hline - Secondary & 1 & 2.50 & 1 & 2.50 & 2 & 2.50 \\
\hline
\end{tabular}


Table 2: Shows the occurrence of phlebotomy the local complications among the control and the study groups. It observed that the highest percentage of occurrence of the local complications before the phlebotomy affected the control group was ecchymosis and hematoma $(50.00 \%)$, while the occurrence of venous spasm was $(37.50 \%)$. On the other hand, the entire study group observed with no evidence of signs and symptoms of local complications $(0.00 \%)$ during the phlebotomy.

Table 2: The Occurrence Percentage of Phlebotomy Local Complications among the Control and the Study Groups.

\begin{tabular}{|c|c|c|c|c|c|c|c|c|}
\hline \multirow{3}{*}{$\begin{array}{l}\text { Phlebotomy Local } \\
\text { Complications }\end{array}$} & \multicolumn{4}{|c|}{ During Phlebotomy } & \multicolumn{4}{|c|}{ After Phlebotomy } \\
\hline & \multicolumn{2}{|c|}{$\begin{array}{l}\text { Control } \\
\text { Group } \\
\mathbf{n = 4 0}\end{array}$} & \multicolumn{2}{|c|}{$\begin{array}{l}\text { Study Group } \\
\mathrm{n}=\mathbf{4 0}\end{array}$} & \multicolumn{2}{|c|}{$\begin{array}{l}\text { Control Group } \\
n=40\end{array}$} & \multicolumn{2}{|c|}{$\begin{array}{l}\text { Study Group } \\
\mathrm{n}=\mathbf{4 0}\end{array}$} \\
\hline & No. & $\%$ & No. & $\%$ & No. & $\%$ & No. & $\%$ \\
\hline - Thrombosis & 0 & 0.00 & 0 & 0.00 & 10 & 25.00 & 0 & 0.00 \\
\hline - Venous spasm & 15 & 37.50 & 0 & 0.00 & 8 & 20.00 & 0 & 0.00 \\
\hline - Local infection & 0 & 0.00 & 0 & 0.00 & 3 & 7.50 & 0 & 0.00 \\
\hline $\begin{array}{l}\text { - Ecchymosis and } \\
\text { hematoma }\end{array}$ & 20 & 50.00 & 0 & 0.00 & 14 & 35.00 & 0 & 0.00 \\
\hline - Needle dislodgment & 0 & 0.00 & 0 & 0.00 & 5 & 12.50 & 0 & 0.00 \\
\hline
\end{tabular}

Table 3: Shows the ordering values of the occurrence of phlebotomy local complications among the control and the study groups. Findings show that the most common phlebotomy local complications of the affected the control and the study groups were the Ecchymosis and hematoma and venous spasm which affected $(85.00 \%)$ and $(57.00 \%)$ of the control group respectively. In addition, it observed that thrombosis, needle dislodgment and local infection were affected $(12.50 \%, 6.26 \%$ and $3.75 \%)$ respectively of the control group. On the other hand, none of the study group patients affected. There was significant difference found between study and control groups in the incidence of occurrence of the phlebotomy local complications.

Table 3: The Ordering Values of the Occurrence of the Local Complications of the Peripheral Venous Phlebotomy among the Control and the Study Groups.

\begin{tabular}{|c|c|c|c|c|c|c|c|c|}
\hline \multirow[t]{2}{*}{$\begin{array}{l}\text { Phlebotomy Local } \\
\text { Complications }\end{array}$} & \multicolumn{2}{|c|}{$\begin{array}{l}\text { Control } \\
\text { Group* } \\
\mathbf{n = 4 0} \\
\end{array}$} & \multicolumn{2}{|c|}{$\begin{array}{l}\text { Study Group* } \\
\mathrm{n}=\mathbf{4 0}\end{array}$} & \multicolumn{2}{|c|}{$\begin{array}{l}\text { Total } \\
\mathrm{n}=\mathbf{8 0}\end{array}$} & \multirow[t]{2}{*}{$\mathbf{X}^{2}$} & \multirow[t]{2}{*}{$\begin{array}{l}\mathbf{P} \\
\text { level }\end{array}$} \\
\hline & NO. & $\%$ & NO. & $\%$ & NO. & $\%$ & & \\
\hline $\begin{array}{l}\text { - Ecchymosis and } \\
\text { hematoma }\end{array}$ & 34 & 85.00 & 0 & 0.00 & 34 & 42.50 & $40.755 * *$ & $<0.001$ \\
\hline - Local infection & 3 & 7.50 & 0 & 0.00 & 3 & 3.75 & $21.587 * *$ & $<0.001$ \\
\hline - Venous spasm & 23 & 57.50 & 0 & 0.00 & 23 & 28.75 & $23.226 * *$ & $<0.001$ \\
\hline $\begin{array}{l}\text {-Needle } \\
\text { dislodgment }\end{array}$ & 5 & 12.50 & 0 & 0.00 & 5 & 6.25 & $11.429 * *$ & $<0.001$ \\
\hline - Thrombosis & 10 & 25.00 & 0 & 0.00 & 10 & 12.50 & $26.475 * *$ & $<0.001$ \\
\hline
\end{tabular}

Table 4: Shows the correlation between the occurrence of the phlebotomy local complications and the patients' age among the control and the study groups. In relation to patient's age the total sample consists of eight patients were in the age ( $20<30$ years), 13 were in the age $(30<40$ years), 28 were in the age $(40<50$ years) and 31 were in the age $(50 \leq 60$ years $)$. As regarding the patients in the age $(20<30$ years $)$, it was seen that the highest percentage of the incidence of the phlebotomy local complications were ecchymosis and hematoma and venous spasm $(62.50 \%$ and $37.50 \%)$ respectively. In relation to patients in the age group ( $30<40$ years), it was observed that the majority of them $(61.53 \%)$ were developed ecchymosis and hematoma, while the minority in the same age $(7.69 \%)$ were developed thrombosis. As regarding the patients in age $(40<50$ years), it was noticed that $(50.00 \%)$ were developed venous spasm. On the other hand $(25.00 \%)$ of the patients were developed ecchymosis and hematoma and $(14.28 \%)$ were developed local infection. Results revealed that the majority $(45.16 \%)$ of patients in the age $(50 \leq 60$ years) were developed ecchymosis and hematoma, while the minority in the same age $(9.67 \%)$ were developed local infection. It noticed that significant difference found between the incidence of occurrence of the phlebotomy local complications and the patient's age of the control and the study groups. 
Table 4: The Correlation between the Occurrence of the Phlebotomy Local Complications and the Patients' Age among the Control and the Study Groups.

\begin{tabular}{|c|c|c|c|c|c|c|c|c|c|c|}
\hline \multirow{3}{*}{$\begin{array}{l}\text { Phlebotomy Local } \\
\text { Complications }\end{array}$} & \multicolumn{8}{|c|}{ Age in Years } & \multirow{3}{*}{$\mathbf{X}^{2}$} & \multirow{3}{*}{$\begin{array}{l}\text { P } \\
\text { level }\end{array}$} \\
\hline & \multicolumn{2}{|c|}{$\begin{array}{l}20<30 * \\
\mathrm{n}=\mathbf{8}\end{array}$} & \multicolumn{2}{|c|}{$\begin{array}{l}30<40 * \\
\mathrm{n}=13\end{array}$} & \multicolumn{2}{|c|}{$\begin{array}{l}40<50 * \\
\mathrm{n}=\mathbf{2 8}\end{array}$} & \multicolumn{2}{|c|}{$\begin{array}{l}50 \leq 60 * \\
\mathrm{n}=31\end{array}$} & & \\
\hline & No. & $\%$ & No. & $\%$ & No. & $\%$ & No. & $\%$ & & \\
\hline Thrombosis & 0 & 0.00 & 1 & 7.69 & 2 & 7.14 & 7 & 22.58 & 0.000 & $(1.000)$ \\
\hline Venous spasm & 3 & 37.50 & 2 & 15.38 & 14 & 50.00 & 4 & 12.90 & $18.75 * *$ & $<0.001$ \\
\hline Local infection & 0 & 0.00 & 0 & 0.00 & 4 & 14.28 & 3 & 9.67 & $24.25 * *$ & $<0.001$ \\
\hline $\begin{array}{l}\text { Ecchymosis and } \\
\text { hematoma }\end{array}$ & 5 & 62.50 & 8 & 61.53 & 7 & 25.00 & 14 & 45.16 & $51.00 * *$ & $<0.001$ \\
\hline Needle dislodgment & 0 & 0.00 & 0 & 0.00 & 1 & 3.57 & 4 & 12.90 & $16.00 * *$ & $<0.001$ \\
\hline \multicolumn{11}{|c|}{$\begin{array}{l}\mathrm{n}=\text { number of patients } * \text { Significant at } \mathrm{p} \leq 0.05 \\
* * \text { Significant at } \mathrm{p} \leq 0.001\end{array}$} \\
\hline
\end{tabular}

Table 5: Shows the correlation between the occurrence of the phlebotomy local complications and the gender among the control and the study groups. Both male and female patients developed more than one phlebotomy local complication at the same time during the days of observations. In relation to patient's gender 39 were males and 41 were females, it was seen $(43.58 \%)$ of male patients were developed ecchymosis and hematoma, while only $(2.56 \%)$ were developed local infection. As regarding the female patients, it was observed that the majority were developed ecchymosis and hematoma and venous spasm (41.46\% and 29.26) respectively, while $(4.87 \%)$ developed local infection. It noticed that there was no significant difference found between the incidence of occurrence of the phlebotomy local complications and the patient's gender of the control and the study groups.

Table 5: The Correlation between the Occurrence of the Phlebotomy Local Complications and the Patients' Gender among the Control and the Study Groups.

\begin{tabular}{|c|c|c|c|c|c|c|}
\hline \multirow[t]{3}{*}{ Phlebotomy Local Complications } & \multicolumn{4}{|c|}{ Gender } & \multirow{3}{*}{$\mathbf{X}^{2}$} & \multirow{3}{*}{$\begin{array}{l}\text { P } \\
\text { level }\end{array}$} \\
\hline & \multicolumn{2}{|c|}{$\begin{array}{l}\text { Male* } \\
\text { n=39 }\end{array}$} & \multicolumn{2}{|c|}{$\begin{array}{l}\text { Female* } \\
n=41\end{array}$} & & \\
\hline & No. & $\%$ & No. & $\%$ & & \\
\hline - Thrombosis & 5 & 12.82 & 5 & 12.19 & 0.000 & $(1.000)$ \\
\hline - Venous spasm & 11 & 28.20 & 12 & 29.26 & 0.000 & $(1.000)$ \\
\hline - Local infection & 1 & 2.56 & 2 & 4.87 & 0.000 & $(1.000)$ \\
\hline - Ecchymosis and hematoma & 17 & 43.58 & 17 & 41.46 & 0.000 & $(1.000)$ \\
\hline - Needle dislodgment & 2 & 5.12 & 3 & 7.31 & 0.000 & $(1.000)$ \\
\hline \multicolumn{7}{|c|}{$\mathrm{n}=$ number of patients $\quad *$ Significant at $\mathrm{p} \leq 0.05 * * *$ Significant at $\mathrm{p} \leq 0.001$} \\
\hline
\end{tabular}

Table 6: Shows the percentage of the performance related to initiating, monitoring, maintaining and discontinuing of phlebotomy among the control group. The total number of observations 40 observations related to phlebotomy. In relation to the washing of hands, the results show that hands washed only by $(17.50 \%)$ correctly, while $(70.00 \%)$ never washed hands throughout procedure. Regarding the checking of the physician written order, it was noticed that $(15.00 \%)$ were correctly checked it, while $(82.50 \%)$ never checked it before initiating phlebotomy. The investigators was observed that none of the observations were reviewed the patient's record for checking the medical diagnosis. In relation to the preparation of the patient, it was seen that $(5.00 \%)$ of the observations were explained the procedure and the fully purpose correctly, while $(75.00 \%)$ just mentioned to the patient that he or she will take blood sample. The investigators was observed that none of the observations were assessed the selected site for phlebotomy. As regards equipment preparation for phlebotomy, it was noticed that $(5.00 \%)$ of the observations were correctly prepared all the needed equipment, while $(90.00 \%)$ were incorrectly and incompletely. As regards assembling equipment at the bedside table, it was noticed that (7.50\%) of the observations were correctly assembling equipment at the bedside table, while $(80.00 \%)$ never performed it.

Concerning the environmental preparations, it was noticed that $(10.00 \%)$ of the observations were correctly prepared the environment, while (82.50\%) never prepared it before initiating phlebotomy. As regards the preparation of the phlebotomy site, it was observed that $(85.00 \%)$ of the observations were incorrectly preparing the site before the insertion, while (15.00\%) never performed it. Regarding the vein puncture, it was seen that $(65.00 \%)$ of the observations were puncture the vein correctly at 15 to 30 degrees angle using upward direction of the bevel and the vein successfully with the first trial puncture, while $(35.00 \%)$ of the observations were not done it correctly and puncture the vein after several trials of puncture. Concerning the discontinuing phlebotomy, it was seen that $(32.50 \%)$ of the observations were done it correctly continued the pressure at the phlebotomy site after withdrawing. On the other hand $(67.50 \%)$ of the observations done incorrectly. As regarding the recoding, the table revealed that $(52.50 \%)$ of the observations were done it incomplete and 
incorrect. On the other hand (12.50\%) of the observations done correctly and complete, while (35.00\%) never performed it.

Table 6: The Percentage Distribution of the Nursing Performance Related to Initiating, Monitoring, Maintaining and Discontinuing Phlebotomy among the Control Group.

\begin{tabular}{|c|c|c|c|c|c|c|}
\hline \multirow{3}{*}{$\begin{array}{l}\text { Nursing Action } \\
n=40\end{array}$} & \multicolumn{4}{|c|}{ Done } & \multirow{2}{*}{\multicolumn{2}{|c|}{ Not Done }} \\
\hline & \multicolumn{2}{|c|}{ Correctly } & \multicolumn{2}{|c|}{ Incorrectly } & & \\
\hline & No. & $\%$ & No. & $\%$ & No. & $\%$ \\
\hline - Wash hands. & 7 & 17.50 & 5 & 12.50 & 28 & 70.00 \\
\hline - Check the written order. & 6 & 15.00 & 1 & 2.50 & 33 & 82.50 \\
\hline - Explain the procedure. & 2 & 5.00 & 30 & 75.00 & 8 & 20.00 \\
\hline - Prepare the equipment. & 2 & 5.00 & 36 & 90.00 & 2 & 5.00 \\
\hline - Assemble the equipment. & 3 & 7.50 & 5 & 12.50 & 32 & 80.00 \\
\hline - Prepare the environment. & 4 & 10.00 & 3 & 7.50 & 33 & 82.50 \\
\hline - Prepare the phlebotomy site. & 0 & 0.00 & 34 & 85.00 & 6 & 15.00 \\
\hline Needle bevel direction- & 4 & 10.00 & 3 & 7.50 & 33 & 82.50 \\
\hline - Needle angle during insertion & 7 & 17.50 & 5 & 12.50 & 28 & 70.00 \\
\hline - Immobilize the vein with thumb & 0 & 0.00 & 0 & 0.00 & 40 & 100.00 \\
\hline - Observe the phlebotomy site. & 0 & 0.00 & 0 & 0.00 & 40 & 100.00 \\
\hline - Apply a sterile dressing cover the site & 0 & 0.00 & 0 & 0.00 & 40 & 100.00 \\
\hline - Labeling the collected specimen. & 5 & 12.50 & 21 & 52.50 & 14 & 35.00 \\
\hline
\end{tabular}

Table 7: Shows the correlation between the needle insertion trials for phlebotomy and the occurrence of phlebotomy local complications among the control and the study groups. In relation to veins had to be punctured, it was observed that phlebitis was developed in $(85.71 \%)$ of the patients whose veins were subjected to more than one trial puncture. As compared (36.36\%) of patients in those whose veins were punctured from the first trial. As regarding the highest percentage of occurrence of the local complications of the phlebotomy. On the other hand the lowest percentage of occurrence (3.03\%) in patients were equally developed venous spasm As regarding the highest percentage of occurrence of the local complications of phlebotomy, it was noticed that $(100.00 \%)$ of patients whose veins were punctured after more than one trial were developed ecchymosis and hematoma. On the other hand, the lowest percentage of occurrence $(14.28 \%)$ in patients was developed thrombosis. There was statistically significant difference between the two groups in relation to the insertion trails for phlebotomy and the occurrence of phlebotomy complications.

Table 7: The Correlation between the Needle Insertion Trials for Phlebotomy and the Occurrence of Local Complications among the Control and the Study Groups.

\begin{tabular}{|c|c|c|c|c|c|c|}
\hline \multirow{3}{*}{$\begin{array}{l}\text { Phlebotomy Local } \\
\text { Complications }\end{array}$} & \multicolumn{4}{|c|}{ Insertion trials } & \multirow[t]{3}{*}{$\chi^{2}$} & \multirow{3}{*}{$\begin{array}{l}\text { p } \\
\text { level }\end{array}$} \\
\hline & \multicolumn{2}{|c|}{$\begin{array}{l}\text { First Trial } * \\
\mathbf{n}=66\end{array}$} & \multicolumn{2}{|c|}{$\begin{array}{l}\text { Several Trials * } \\
n=14\end{array}$} & & \\
\hline & No. & $\%$ & No. & $\%$ & & \\
\hline - Thrombosis & 0 & 0.00 & 2 & 14.28 & $8.382^{* * *}$ & $(<0.008)$ \\
\hline - Venous spasm & 2 & 3.03 & 5 & 35.71 & $4.033^{* *}$ & $(<0.073)$ \\
\hline - Local infection & 4 & 6.06 & 7 & 50.00 & $4.944^{*}$ & $(<0.042)$ \\
\hline -Ecchymosis and hematoma & 6 & 9.09 & 14 & 100.00 & $41.608^{* *}$ & $(<0.001)$ \\
\hline -Needle dislodgment & 2 & 3.03 & 4 & 28.57 & $17.892^{* *}$ & $(<0.001)$ \\
\hline
\end{tabular}

Table 8: provides data about the percentage of pain occurrence and its severity during and after the phlebotomy among the control and the study groups. It was observed that the highest percentage of the patients in the study group (100.00) were not complained of any form of pain during phlebotomy, while $(17.50 \%)$ of the patients in the control group were developed moderate degree of pain. However, only $(2.50 \%)$ developed mild pain in the same group. Concerning after the phlebotomy, it noticed that none of study group patients complained of pain, while $(10.00 \%)$ of the control group, patients equally developed either mild or moderate pain. The table illustrates that there were significant difference in the severity of pain between the two groups during and after the phlebotomy.

Table 8: The Percentage of Pain Occurrence and its Severity during and After the Phlebotomy among the Control and the Study Groups.

\begin{tabular}{|l|l|l|l|l|l|}
\hline Pain Severity & \multicolumn{2}{|l|}{$\begin{array}{l}\text { Control Group } \\
\mathbf{n = 4 0}\end{array}$} & $\begin{array}{l}\text { Study Group } \\
\mathbf{n = 4 0}\end{array}$ & $\begin{array}{l}\text { P } \\
\text { level }\end{array}$ \\
\cline { 2 - 4 } & No. & \% & No. $\%$ & \multirow{2}{*}{$\%$} & \\
\hline During the Phlebotomy & & $8.889^{*}$ & $(<0.001)$ \\
\hline
\end{tabular}




\begin{tabular}{|c|c|c|c|c|c|c|}
\hline No pain & 32 & 80.00 & 40 & 100.00 & & \\
\hline Mild pain & 1 & 2.50 & 0 & 0.00 & & \\
\hline Moderate pain & 7 & 17.50 & 0 & 0.00 & & \\
\hline \multicolumn{5}{|c|}{ After the phlebotomy } & & \\
\hline No pain & 32 & 80.00 & 40 & 100.00 & \multirow[t]{3}{*}{$8.889^{*}$} & \multirow[t]{3}{*}{$(<0.001)$} \\
\hline Mild pain & 4 & 10.00 & 0 & 0.00 & & \\
\hline Moderate pain & 4 & 10.00 & 0 & 0.00 & & \\
\hline
\end{tabular}

$\mathrm{n}=$ number of patients *Significant at $\mathrm{p} \leq 0.05 * *$ Significant at $\mathrm{p} \leq 0.001$ same patient

\section{Discussion}

Phlebotomy is the easiest, safest, seemingly low cost supplies and virtually commonest in daily medical practice used for diagnostic purposes for obtaining blood samples for laboratory tests ${ }^{(58)}$. Phlebotomy is representing as a problem if it performed incorrectly; it will lead to local, thus it should look after and performed by a competent nurse to prevent the development of complications and patients' suffering ${ }^{(59)}$. The main purpose of this study was to evaluate the effect of best practices nursing guideline for quality improvement and patient safety in phlebotomy.

Results showed that there was high incidence of phlebotomy local complications among the control group patients. From the investigators observations; this result may be due to lacking of nursing skills related to different aspects of phlebotomy. In addition, it may be due to inadequate basic education, unavailability of orientation and in-service training programs as well as postgraduate courses ${ }^{(60)}$.

The findings of the present study indicated that, local complications of phlebotomy which were developed among the control and the study groups were ecchymosis and hematoma and venous spasm which affected $(85.00 \%)$ and $(57.00 \%)$ of the control group respectively. In addition, it observed that thrombosis, needle dislodgment and local infection were affected $(12.50 \%, 6.26 \%$ and $3.75 \%)$ respectively of the control group. On the other hand, none of the study group patients affected. The present findings also agreed with Chukhraev and Grekov (2000) ${ }^{(20)}$, who found that most of total venipuncture complications were $(28.00 \%)$, including spontaneous rupture of the vein $(6.00 \%)$, obliteration of vessel $(4.00 \%)$, superficial phlebitis $(8.00 \%)$, external bleeding from the vein $(5.00 \%)$, and local allergic reactions $(5.00 \%)$.

Regarding to the percentage of the occurrence of the phlebotomy complications after the vein puncture, the present findings revealed that in the control group the highest percentage in the first day, which affected these patients, were ecchymosis and hematoma. This may developed due to incorrect puncture of the vein or incorrect selection of vein appropriate with the selected needle gauge. From the observation, it noticed that patients who bruise easily could develop a hematoma when large gauges needles used, owing to trauma to the vein during puncture. Hematomas were most often related to kinking the vein during an unsuccessful venipuncture attempt, when discontinuing of the needle without pressure held over site after removal of the needle and when applying the tourniquet too tightly above a previously attempt venipuncture site ${ }^{(61)}$.

From the investigators' viewpoint, there are certain preventive measures the nurse can used in order to prevent the occurrence of hematoma, such as the nurse should apply the tourniquet just before venipuncture for elderly patients. Patients on corticosteroid or paper-thin skin, use a small needle, preferably 20 or 22 gauge as well as using a blood pressure cuff instead of rubber tourniquet to fill the vein ${ }^{(62)}$. However, in this respect Karadag and Grgulu (2000) ${ }^{(9)}$, stressed that nurses need to develop their competence in the phlebotomy, need to demonstrate competence and experience in the vein puncture. Furthermore, nurses should apply evidence base for good practices to avoid the occurrence of ecchymosis and hematoma ${ }^{(63)}$

Considering the patients' age and its relation to the incidence of local complications of the phlebotomy the results of the present study, revealed that the most common complications occurred at the early age $(20<30)$ years was phlebitis, while the complications at older age $(50 \leq 60)$ years was thrombophlebitis. These results were congruent with Meeker and Rothrock $(2000)^{(4)}$, Lueckenotte $(2000)^{(64)}$ and Nancy (2004) (65) who found that at late stage of the age $(50 \leq 60$ years), occur a changes in the vein wall due to aging process, the veins become thinner, less elastic and subcutaneous tissue lessens. In the same line Rambo and Wood (2003) (66) revealed that the changes in the veins wall due to aging process of the veins, renders the walls more fragile and less elastic this would lead to circulatory changes and increase of the peripheral resistance and incidence of phlebitis ${ }^{(67},{ }^{68},{ }^{69)}$.

Regarding to the patients' sex, finding of the present study revealed that there were no significant difference in the incidence of phlebitis or other local complications of phlebotomy in both sex. These results were not in agreement with Abdel Wahab (1994) ${ }^{(70)}$ who reported that the incidence of phlebitis was about twice in female patients as compared to its occurrence in male patients.

Regarding to the patients' activity level, the present findings indicated that there was a significant difference found between the incidence of the occurrence of the local complications of phlebotomy and the patients' activity level. The results revealed that all bed-ridden patients affected with the signs of phlebitis; this may attribute to immobilization and slow rate of the venous circulation because of decreases of the cardiac 
output. In addition, the majority of bed-ridden patients developed local infection; this may be due to decrease in the muscle tone, reduced muscular pump's action on the vein, circulatory stasis, damage to the intima of the vein enhancing inflammatory reaction and possible clot formation. This finding was in congruent with Porth and Kunert (2002) ${ }^{(2)}$ who found that venous stasis and increased blood coagulation may occurred for bedridden patients due to dehydration and hypovolemia. Moreover, bed-ridden patients were also developed phlebitis and thrombophlebitis ${ }^{(71,72,73)}$.

Regarding to the patients' educational level, the present findings revealed that there was no significant difference found between the incidence of phlebitis or other local complications of phlebotomy and the patients' educational level either of the control group or the study group patients. These results were not in agreement with Ashera et al (1993) ${ }^{(18)}$, who found that patients having high educational level were less liable to develop phlebotomy local complications; since they were aware about the early clinical signs and symptoms of any abnormality at the phlebotomy site. Moreover, they were able to maintain the phlebotomy site through keeping the dressing intact and clean ${ }^{(74,75)}$.

As regards the needle size, the present findings revealed that the majority of patients in the control group were developed phlebitis since the nurses used large needle gauge. This was in agreement with Speechley $(2006)^{(39)}$ who reported that the larger the gauge of the needle, the greater the irritation produced. In the same line Burrows $(2005)^{(17)}$ and Knight, Dubree and Shmerling $(2003)^{(44)}$ stressed that using a small gauge needle to decrease the chance of phlebitis ${ }^{(76,77,78)}$. For the study group, it observed that a small gauge needle limits the size of the wound in the vein and the amount of foreign body within it, thus reduces the percentage of the incidence of phlebitis and thrombosis.

In relation to the phlebotomy site, the investigators selected the phlebotomy site based on Mapping out a Plan. This was in agreement with Scales $(2005){ }^{(68)}$ who recommended that the selection of forearm or hand veins were best for phlebotomy, since they were large, easily accessible and accommodate large needle. This was not in agreement with Millam and Potter (2002) ${ }^{(71)}$ who found that hand veins were small, thin walled, and easily irritated. So a small gauge needle should use to prevent direct trauma to the veins wall ${ }^{(79)}$.

Regarding the nursing performance related to initiating, maintaining and discontinuing the phlebotomy for the control and the study groups, the first step for initiating the phlebotomy was hand washing. The present results revealed that few of the nurses washed their hands before initiating the phlebotomy. In this respect Issam, Raad and Gerald (1998) ${ }^{(80)}$ stressed that soap and water is adequate for hand washing prior phlebotomy. In addition, the nurse should start the phlebotomy with hand washing because it has shown to decrease significantly the potential risk of contamination and cross infection ${ }^{(81)}$.

Considering check of the physician written order for phlebotomy, the present result denoted that the minority of the nurses correctly checked the written order to identify the orders blood investigations required. In this regard, Clack $(2003){ }^{(5)}$ recommended that the nurse is responsible for initiating the phlebotomy ${ }^{(82)}$.

Concerning the preparation of the patient, the results denoted that none of the nurses explained the procedure and its purpose fully to the patient. Diploma $(2000)^{(31)}$ stressed the importance of a cheerful smile and good explanation of what has to done, this is very important to gain the patient's cooperation and confidence and to alleviate the anxiety. Finding of the present study showed that most of nurses not considered the comfortable position for the patient. Hirnle and John $(2005)^{(25)}$ stressed that the patient should be in comfortable position, a suitable explanation about the procedure should give, the sleeve of patient's gown is to remove, cutting of the hair at the selected site for phlebotomy has to do if necessary and the limb should splinted and supported by pillow. The study findings revealed that nurses practice regarding patient's preparation and care before and during the phlebotomy were incomplete ${ }^{(83)}$.

This may attributed to inability of the nurses to assume their responsibilities toward their patients due to lack of their skills about the needed patient's preparations. In this respect, Nash (2003) ${ }^{(12)}$ emphasized the importance of patient care before and during the phlebotomy. It should include measuring the vital signs; observation of the phlebotomy site, inspecting the patient for abnormal reactions, attention should give to the patient psychological condition. In addition, Millam $(2006){ }^{(15)}$ stated that no one should start the phlebotomy on patients unless provide the patient with adequate instruction and make the patient feels comfortable with the procedure $^{(84,85,86,87)}$.

As regard, the environmental preparation results revealed that the majority of the nurses did not prepare the environment. In this regard, Timby and Smith (2004) ${ }^{(88)}$ stressed that the nurse should prepare the environment before starting the phlebotomy, because it facilitates the work in private, calm and comfortable environment and to prevent possible contamination. Proehl (2000) ${ }^{(89)}$ indicated that the nurse should check the cleanliness, ventilation of room, adequate lighting was important that the vein might be readily visualized ${ }^{(90)}$.

The present findings related to the preparation of equipment and supplies essential for phlebotomy, revealed that few of the nurses prepared all the required equipment. This may attributed to unavailability of a procedure manual; library facilities affiliated to the hospital, also workshops were not available. On performing the phlebotomy, it observed that assembling of all needed equipment at bedside done only by few of the nurses, 
but when the nurses needed additional equipment e.g. scissors or adhesive tape, they interrupt their work and go to bring the equipment. It was a waste of time and effort, which also may lead to patient's disturbance. Therefore, the required equipment should be prepared for use at bedside before starting the phlebotomy. In this respect, Trimble (2003) ${ }^{(91)}$ indicated that the nurse should assemble all needed equipment at the bedside to prevent interruption during the work ${ }^{(92)}$.

Concerning the selection of the phlebotomy site to used, it observed that few of the nurses usually select and use one or two sites. This may attributed to inadequate knowledge of the anatomy of the blood vessels and the related structures. In this respect Lewis, Heltkemper and Dirksen (2004) ${ }^{(86)}$ ascertained the importance of reviewing the anatomy of blood vessels and learning the related position of nerves and bones before phlebotomy ${ }^{(93)}$.

Regarding the use of previously injured veins for phlebotomy, the present results showed an increase in the incidence of occurrence of phlebitis. In this regard, Porth and Kunert (2002) ${ }^{(2)}$ attributed this to the fact that when a vessel is injured endothelial damage could reduce prostacyclin synthesis resulting in regional vasoconstriction and platelet aggregation in the damaged area and possibly thrombophlebitis. Moreover, using injured sites for phlebotomy may contribute to microbial contamination ${ }^{(94)}$.

In relation to the phlebotomy site preparation, the findings indicated that not all nurses practiced cutting of the hair at the phlebotomy site even when the arm was excessively hairy. This was because cutting the hair over the phlebotomy site was not included in the hospital policy and the nurses were not aware of its importance. In this respect Field, Workman (2002) ${ }^{(95)}$ recommended cutting of hair because it facilitates finding the veins and makes removal of the adhesive tape less painful when the infusion discontinued. Masoorli (2005) (74) added that cutting of hair was better than shaving because, it reduces the risk for injury, which may result from shaving and increases the possibility of skin microbes ${ }^{(96,97)}$.

Regarding the methods used to distend the vein, it was observed that the majority of the nurses were used the tourniquet, while few numbers of them used other methods such as open and close the hand, place the part in dependent position and milk the vein upward. This was in agreement with Lenhardt, Seybold and Kimberger (2004) ${ }^{(99)}$ who ascertained that the nurse should be familiar with other methods used to distend the vein rather than applying tourniquet, such as placing the part in a dependent position for several minutes or by warming the entire extremity by applying warm towels or by immersion in warm water. Regarding arm position and bed linen protection, the observations indicated that none of the nurses put patient's arm over a protective waterproof pillow or even a sheet to prevent soiling of the bed linen. In this regard, Masoorli, Angeles and Barbone (2000) ${ }^{(100)}$ indicated that the arm should extend on a pillow with a waterproof cover or a clean paper towel to protect the bed linen ${ }^{(101,102)}$.

Regarding to the phlebotomy site disinfection, it observed that most of the nurses disinfected the phlebotomy site with alcohol sponge and did not follow the correct principle. In this regard Rosenthal (2004) ${ }^{(103)}$ recommended that the nurse should apply antiseptic and disinfectant agents and the phlebotomy site should be disinfected in a circular motion from the inner part of the site to the outer part about $7.5 \mathrm{~cm}$ in diameter using moistened alcoholic sponge $70 \%$ then after drying clean with Betadine $10 \%$. It also observed that most of the nurses did not lay the sterile needle in a sterile surface and let the needle uncovered until the site was prepared. Prolonged exposure to the air or contact with a surface such as nurses' hands will contaminate the needle. In accordance with Martin (2005) ${ }^{(104)}$ the sterile needle should be laid in or on a sterile surface until arm is prepared to prevent the occurrence of local infection ${ }^{(105,106)}$.

Considering the bevel direction, the observations denoted that most of the nurses did not consider the needle bevel direction; therefore, they punctured the vein with the bevel facing downward, although the bevel of the needle should face upward during the needle insertion. In this regard, Millam (2005) ${ }^{(107)}$ indicated that the nurse should draw the skin below the insertion site taut, using the thumb of the nondominant hand, use thumb to apply tension down on tissue and vein about $5 \mathrm{~cm}$ distal to injection site in order to avoid rolling the vein. In addition, to direct the needle with bevel upward when a vein lumen is larger than the needle and downward; when entering a small vein and lumen approaches the size of the needle. Bannerjee (2005) added that the nurse should puncture the skin parallel to the path of the vein with the bevel up and the needle at 15 to 30 degrees angle to prevent the veins injury and the development of hematoma and ecchymosis ${ }^{(108,109)}$.

Concerning nursing care after phlebotomy, it observed that covering the phlebotomy site with a sterile dressing not practiced by most of the nurses; they left the site uncovered or covered only by adhesive tape. The phlebotomy site should cover by sterile gauze to avoid contamination and prevent the occurrence of local infection.

Regarding the percentage of occurrence of pain and its severity during and after the phlebotomy, the findings showed that the highest percentage of the patients in the study group were not complained of any form of pain during the phlebotomy, while the majority of the patients in the control group were developed either moderate or mild pain. This may be due to lack of nursing care strategies started from the pre- insertion stage until the removal stage of the phlebotomy. In this regard Potter and Perry (2005) ${ }^{(6)}$ stressed that psychological 
strategies can be achieved through simple preparation, explanation of the purpose of the needle insertion for the patient. If possible given a chance for the patient to participate in the selection of the site of vein puncture to gain patient's cooperation and/or acceptance, as well as reduce fear and anxiety. In addition, the nurse should be sure to touch patient's hand for reassurance ${ }^{(110)}$.

Finally, comfortable position enhances accessibility to the venipuncture, which helps in relaxation and promotes patient's comfort. These are important because anxious patient is at increased risk for vasovagal reaction, which could make veins hard to find. Moureau (1999) ${ }^{(11)}$ added that venous spasm, which is the most common form of pain, might occur suddenly. The nurse can detect its occurrence through patient's complain of sharp pain at phlebotomy site traveling up the arm ${ }^{(112,113)}$. Nerve, tendon or ligament damage are less common complications may be resulting from poor nurses' knowledge of anatomy or poor insertion technique of the peripheral venous phlebotomy which could cause accidental injury to any of these structures.

Prevention of complications is better than management. Prevention meant to improve patients' outcome and reduce health care cost and hospital stay. In addition, prevention will minimize patient's fear, stress and pain provoked by phlebotomy re-puncture. The phlebotomy nursing care strategies started from the prephlebotomy stage until the removal stage. These strategies are both psychological and physical. These essential required strategies aimed to prevent psychological and physical trauma in the three phases of phlebotomy care before, during and after the puncture.

\section{Conclusions}

This study seeks to determine the effect of patient safety and quality improvement nursing interventions for phlebotomy utilizing a procedure manual. Based on the results of this study, it can concluded that: There were significant differences found between control and study groups in the incidence of occurrence of the local complications of phlebotomy.

- Infection and hematoma were the most common local complications of phlebotomy.

- The incidence of occurrence of the local complications was high among patients whom use of large needle gauge or use of small veins for phlebotomy.

- There was incompetence of nurses' performance regarding the initiating, maintaining and discontinuing the phlebotomy.

- The incidence of occurrence of the local complications was high among patients who had several insertion trials for phlebotomy.

- The various factors affected the incidence of the occurrence of the local complications were divided into the patients' factors and nurses' performance factors were found to bear more heavily on the incidence of the occurrence of the local complications.

- Highest occurrence of pain during and after the phlebotomy may be because of lacking of patient's preparations and explanation.

\section{Recommendations}

Based on the findings of the present study, the following recommendations derived and suggested.

\section{- Recommendations for Patients:}

-Prepare the patients psychologically and physically.

-For the phlebotomy site using the most distal location and move up as necessary.

\section{- Recommendation for Nurses:}

-Training program should established and conducted on regular basis for newly appointed nurses are already in contact with the patients. The training would related to theoretical and practical aspects of phlebotomy. Practical part carried out under supervision using three dimensional simulation models and to practice on patients later. -Refresh courses, conferences established for nurses to provide them with the recent advances in phlebotomy.

\section{- Recommendation for Administration:}

- A team specially trained in the area of phlebotomy being responsible for the training program.

- Nursing procedure manual should be available on the patients' wards.

- Regular supervision of the nurses being responsible for intravenous infusion on the wards.

\section{-Recommendation for Future Researches:}

- As infection and hematomas were the most common local complications of the phlebotomy, proper management needs to investigate.

- Determine the effect of the nursing intervention on the prevention of occurrence of the phlebotomy local complications among patients with chemotherapy and/or whom undergoing anticoagulant drugs. 


\section{References}

[1]. Anderson D, Novak P. Mosby's Medical, Nursing, Allied Health Dictionary. $6^{\text {th }}$ ed. London: Mosby: A Harcout Health Sciences Company, 2002; 218, 824, 922- 5 .

[2]. Porth C, Kunert M. Pathophysiology Concepts of Altered Health States. $6^{\text {th }}$ ed. Philadelphia: Lippincott Williams \& Wilkins, 2002; 256-69.

[3]. Cahill M, McCann S, Smith J. Nursing Procedures: Intravascular Therapy. $4^{\text {th }}$ ed. Lippincott Williams \& Willing Company, 2004; 272-92.

[4]. Meeker M, Rothrock J. Alexander's Care of the Patient in Surgery: $11^{\text {th }}$ ed. London. Mosby Company, 2000; 161-242.

[5]. Clack T. Jouanna Briggs Institute for Evidence based Nursing, Margaret Graham Building and Royal Adelaide Hospital. Best Practice: Evidence Based practice Information Sheets for Health Professionals: Management of Peripheral Intravenous Devices, 2003; 2 (1): $1-6$

[6]. Potter P. Perry A. Fundamentals of Nursing. Fluids, Electrolytes and Acid Base Balance. $6^{\text {th }}$ ed. United States. Mosby Co, 2005; 892-908.

[7]. Lundgren A, Christina A. Factors influencing nurses' handling and control of peripheral intravenous lines an interview study. International Journal of Nursing, 2002; 32 (2): 131-42.

[8]. Luckmann J. Saunders Manual of Nursing Care: Intravenous Fluid Therapy. W.B Saunders Co, 1997; 245- 63.

[9]. Karadag A, Grgulu S. Effect of two different short peripheral catheter materials on phlebitis development. Journal of Infusion Nursing, 2000; 30 (3): 158- 66

[10]. Fuerst N, Sherman J, Sherman R. I.V therapy that clicks. Nursing, 2005; 35 (5): 50-1.

[11]. Perry A, Potter P. Clinical Nursing Skills and Techniques: Intravenous and Vascular Access Therapy. $4^{\text {th }}$ ed. Mosby Co, $2003 ; 652-$ 70.

[12]. Nash P. Clinical Nursing Skills and Techniques. Parenteral Medications. $6^{\text {th }}$ ed. Philadelphia: U.S.A. Mosby Co, 2003; 693-761.

[13]. Kelenn G, Ma J. Emergency Medicine Just the Fact: $2^{\text {nd }}$ ed. New York: Resuscitative Problems and Techniques. McGRAW- HILL Co, 2004; 33- 4.

[14]. Timby B, Smith N. Introductory Medical - Surgical Nursing: Caring for Requiring Intravenous Therapy. $8^{\text {th }}$ ed. Philadelphia, Lippincott Williams \& Willing Company, 2004; 269- 83.

[15]. Millam W. Nursing Procedures \& Protocols: Intravascular Therapy: Protocols \& procedures. Philadelphia. Lippincott Williams \& Willing Company, 2006; 159- 266.

[16]. Ross P, Bohony J. 9 Common I.V. Complications and What to do about them. American Journal of Nursing, 2002; 93(16):45-9.

[17]. Burrows S. Complications with the Use of Venous Access Devices. http:// www. Uspharma cist.com/oldformat.asp, 2005; 90-5.

[18]. Ashera A, Mohamed N, Abdou L, El Saied H. The Effect of Changing I.V. Tubing and Percutaneous Needle Sites on the Thrombophlebitis. Fourth International Scientific Nursing Congress on Ethical Issues and Health care Implications for Education, Practice and Research: June 28-30, 1993; Faculty of Nursing, University of Alexandria.

[19]. Hospital Record Main University Hospital. Alexandria, Egypt, 2006.

[20]. Chukhraev A, Grekov I. Local complications of nursing interventions on peripheral veins. Journal of Infusion Nursing, 2000; 23 (3): 167-9.

[21]. Palefski S. The infusion nurse and patient complication rates of peripheral - short catheters: a prospective evaluation. Journal of Infusion Nursing, 2001; 24 (2): 113- 23.

[22]. Bergerson L, Lopez V, Molassiotis A. An Intervention study to evaluate nursing management of peripheral intravascular devices. Journal of Infusion Nursing, 2005; 27 (3): 322-31.

[23]. Lammon c, Foote A, Leli P, Ingle J, Adams M. Clinical Nursing Skills: Administrating Intravenous Therapy. W.B Saunders Company, 2004; 628-61.

[24]. Kemp D, Pillitteri G. Evidence Based Nursing, 2000; 13 (2): 47-52.

[25]. Hirnle S, John B. Fundamentals of Nursing: Human Health and Function: Intravenous Therapy. $2^{\text {nd }}$ ed. Philadelphia: Lippincott Company, 2005; 547- 77.

[26]. Person M. Guideline for Prevention of Intravascular Device Related infections. The Hospital Infection Control practices advisory Committee, Centers for Disease Control and Prevention, Atlanta, U.S.A. 2004.

[27]. Smeltzer S, Bare B. Brunner \& Sunddarth's Textbook of Medical Surgical Nursing: $4^{\text {th }}$ ed. Fluid and Electrolytes: Balance and Disturbance. Philadelphia. Lippincott Williams \& Willing Company, 2004; 283- 92.

[28]. McCann J. Fluid and Electrolytes: Made Incredibly Easy: I.V fluid replacement. $2^{\text {nd }}$ ed. USA: Springhouse Company, 2002; 288301.

[29]. Taylor C, Lillis L and Lemone P. Fundamental of Nursing the Art and Science of Nursing Care. $2^{\text {nd }}$ ed. Philadelphia: U.S.A. Lippincott Williams, 2001; 594 - 604.

[30]. Broome, Bare B. Textbook of Medical - Surgical Nursing 10 $0^{\text {th }}$ ed. Philadelphia: U.S.A. W.B Sunders Co. 2004; 842-6, 1999; 90(2):43-7.

[31]. Diploma L. Intravenous Solutions Which one's right for your patient? Nursing, 2000; 19(4): 62.

[32]. Baily D. Total Parenteral Nutrition. Nursing, 2001; 31 (8): 286-7.

[33]. Love's, Cason. Intravenous therapy. http://www.collegeofparamedics.org/con, 2003; 1-15.

[34]. Taylor C, Lillis C, LeMone P. Fundamental of Nursing the Art \& Science of Nursing: Fluid, Electrolyte, and Acid Base Balance. $4^{\text {th }}$ ed. Philadelphia: Lippincott Company, 2003; 612- 19, 1300- 20.

[35]. Schrefer D. Henderson L. Fundamentals of Nursing: Caring and Clinical Judgment: Medication Management, Fluid and Electrolytes Balance, Health - Perception - Health Management Pattern. Philadelphia: W.B Saunders Company, 2000; 574-83, 76475

[36]. Craven R, Hirnle C. Fundamentals of Nursing: Human Health and Function: Intravenous Therapy, Medication Administration. $4^{\text {th }}$ ed. Philadelphia. Lippincott Williams \& Willing Company, 2003; 566- 73, 575- 609.

[37]. Phillips L. Manual of I.V. Therapeutics: Equipment, Techniques for peripheral Intravenous Therapy, Complications of Intravenous Therapy, Intravenous Therapy Special Problems. F.A. Davis Company, 2000; 137- 69, 179- 213, 227-63, 273- 94.

[38]. Beir I. Peripheral Intravenous Nutrition therapy: outpatient, office- based administration. Alternative Medicine Review, 2000; 5 (4): 347- 54.

[39]. Speechley V. The Nurses' role in the intravenous management. Nursing Times, 2000; 80(5): 31-2.

[40]. Rebecca S. Legal perils of I.V therapy. Nursing, 2000; 30 (8): 30-4.

[41]. Pirmohamed M. Intravenous therapy published. Postgraduate Medical Journal, 2004; 80(939):1-6.

[42]. Durham NC. Types of Intravenous Devices. http://www.webmaster.com, 2003; 1- 2.

[43]. Speechley V. Intravenous therapy: peripheral/central lines. Nursing, 2006; 26 (3): 95- 100. 
[44]. Knight J, Dubree M, Shmerling Intravenous Therapy: Peripheral Vascular Access.http://www.vumcpolicies.mc. vanderbilt.com, 2003; 1-7.

[45]. Hadaway L. I.V rounds: choosing the right vascular access device, Part I: find out how your needs and therapy influence the choice. Nursing, 1999; 29 (2): 18.

[46]. Burrows C. Take step toward making better: I.V needle selection. Nursing, 2004; 34 (12): 32-3.

[47]. McCurdy R. Intravenous Therapy: Equipment, Techniques, and Complications. http://www.ceontime.com/nursing/studies, 2003; 18 .

[48]. Davis P, Kenny G. Basic Physics and Measurement in Anesthesia: Pressure. $5^{\text {th }}$ ed. London. Butterworth Heinenmann Co, 2005; 19 .

[49]. Zimmerman F, Nicoll L, Amber K. CDC Guidelines for peripheral intravenous therapy, 2003; an integrative review of literature. The Online Journal of Knowledge Synthesis for Nursing, 2006; 30 (12):123-9.

[50]. Du Gas M, Millam D. Are Nurses Prepared to Perform Intravenous Therapy? Nursing, $2004 ; 34$ (8): 43.

[51]. Scherer D. Intravenous Therapy Package. http://www.i.vteam.com.august, 2001; 1-23.

[52]. Ross K, Jenner E. Intravenous infusion a cause for concern? Nursing Times, 2004; 73 (2): 156-8.

[53]. Metheny, Potter P. Clinical Nursing Skills and Techniques. $4^{\text {th }}$ ed. Philadelphia: Mosby. 2002: 624-8.

[54]. Mitchell B, Erb G. Techniques in Clinical Nursing: Intravenous Therapy. $3^{\text {rd }}$ ed. Addison- Wesley Publishing Co, $2000 ; 355-83$.

[55]. Thomas W, Nicol M, Bavin C, Turner S. Essential Nursing Skills: I.V Therapy. $2^{\text {n }}$ Lippincott Williams \& Willing Company, 2003; 97- $125^{\mathrm{d}}$ ed. London; Mosby Company, 2003; 55- 73.

[56]. Fortunato M, Perry A, Potter P. Nursing Interventions and Clinical Skills: Intravenous Therapy. $2^{\text {nd }}$ ed. London. Mosby Company, $2001 ; 692-725$.

[57]. Michael C. Flow problems. Nursing, 2004; 34 (11); 40.

[58]. Mayer B. Dosage Calculations Made Incredibly Easy. Parenteral Administration. $2^{\text {nd }}$ ed. Pennsylvania. Springhouse Co, 2002; 20432.

[59]. Kelli R. Monitor Outcomes for safer infusion therapy. Better resource management. Nursing Management, 2003 ; 34 (5): $22-5$.

[60]. Terry J, Baranowski L, Lonsway R. Intravenous Therapy Clinical Principles and Practice: Obtaining Vascular Access. W.B Saunders Company, 2002; 359-550.

[61]. Luckmann J, Sorensen K. Medical - Surgical Nursing a Psychophysiologic Approach:

[62]. Fluid and Electrolytes Imbalance. $2^{\text {nd }}$ ed. Philadelphia. W.B. Saunders Company, 2000; 216- 27.

[63]. Janet L, Marie M. Competent I.V management, Part II. Implementation of fundamental principles and practice standards regarding. Peripheral intravenous therapy. Intravenous Nursing Infusion, 2005; 23 (65): 4450.

[64]. Blum P. Controlling Pain: Easing the discomfort of venipuncture what to do when your patient needs immediate I.V. therapy but is afraid of needle. Nursing, 2004; 34 (3):30.

[65]. Lueckenotte A. Gerontological Nursing $2^{\text {nd }}$ ed. Integumentary System. Philadelphia. Harcourt Health Science Co. $2000 ; 655-7$.

[66]. Nancy L. Tips for inserting I.V in older patient. Nursing, 2004; 34 (7): 50-2.

[67]. Rambo B, Wood L. Nursing Skills for Clinical Practice: Intravenous Therapy. $3^{\text {rd }}$ ed. W.B. Saunders Co, 2003 ; $661-78$.

[68]. Ebersole P, Hess P. Toward Healthy Aging: Age Related Changes. $5^{\text {th }}$ ed. New York: Mosby Co. 2001; 85-91.

[69]. Scales K. Art and science in intravenous focus. Vascular access guide to peripheral venous cannulation. Nursing Standard, 2005; 19 (49): 48-52.

[70]. Stead L, MacDonald B, Jirsa A. The Lippincott Manual of Nursing Practice: I.V. Therapy. $6^{\text {th }}$ ed. Philadelphia: Lippincott Company, 2001; 56-71.

[71]. Abdel Wahab S. Study of Factors Bearing on Incidence of Infusion Phlebitis. Doctor, Thesis. Alexandria University. Faculty of Nursing; 1994.

[72]. Millam A, Potter P. Clinical Nursing Skills Techniques: Initiating Intravenous Therapy. $5^{\text {th }}$ ed. Philadelphia: Mosby Company, 2002; 560- 88 .

[73]. McCann J, Holmes N. Illustrated Manual of Nursing Practice: I.V Therapy. $3^{\text {rd }}$ ed. Philadelphia. Lippincott Williams \& Willing Company, 2002; 97- 125 .

[74]. Timby B. Fundamental Skills and Concepts in Patient Care. $6^{\text {th }}$ ed. Philadelphia: J.B Lippincott. Company, 2000; 73 8-9.

[75]. Suddarth D. The Lippincott Manual of Nursing practice: I.V therapy. Philadelphia, Lippincott Co, $2001 ; 79-94$.

[76]. Dochterman J, Grace H. Current Issues in Nursing: Evidence - based practice: A Tool for Clinical and Managerial Decision Making. $6^{\text {th }}$ ed. Philadelphia: Mosby: A Harcout Health Sciences Company, 2001; 60- 8.

[77]. Hadaway L. Infusing without infection. Nursing, 2003; 33 (10): 58-63.

[78]. Alexander J, Holder C. A new and improved guide to I.V therapy. American Journal of Nursing, 2004 ; 90 (2): $43-7$.

[79]. Metheny L Snively P. Nursing Intervention and Clinical Skills. Philadelphia: Mosby. 2005; 324-6.

[80]. Gerberding J, Fleming D, Snider D. Guidelines for Prevention of Intravascular Catheter - Related Infections: Morbidity and Mortality Weekly Report. Mosby Company, 2002; 51(10): 1-29.

[81]. Issam I, Raad and Gerald P. Infectious complications of indwelling vascular catheters. The section of infectious diseases, department of medical specialties. The University of Texas. Clinical Infect Control Journal 1998; 15 (8): 197-210.

[82]. Thibodeau G, Patton K. Structure and Function of the Body. 12 ${ }^{\text {th }}$ ed. Philadelphia: Mosby Co. 2004; 312-3.

[83]. Williams P, Warwick R. Gray's Anatomy: Angiology. 35 ${ }^{\text {th }}$ ed. London: Longman Company, 2005; $704-6$.

[84]. Masoorli T. Intravenous Therapy Handbook: Learn how to choose the best I.V. site, document procedures, deal with complications and more. Nursing, 2003; 33 (10): 48.

[85]. Fahey V. Vascular Nursing: Clinical Assessment of the Vascular System, Intravenous Monitoring and Catheter Care. $3^{\text {rd }}$ ed. Philadelphia: W.B Saunders Company, 2003; 50- 9, 392- 465.

[86]. Lewis S, Heltkemper M and Dirksen S. Medical Surgical Nursing Assessment and Management of Clinical Nursing. ${ }^{\text {th }}$ ed. Philadelphia: Mosby. 2004; 60.

[87]. Beguin S. Person Education. Intravenous AdministrationTechniques, 2004; 1-10. @ http://chest_wilsondrugguides1Medication\%20 Adminstration\%20 Techniques Injection.Htm.

[88]. Smith E, Greig J. Local warming of the hand and lower arm improved successful peripheral venous cannulation and reduce insertion time. EBN Journal, 2004; 56 (6): 412.

[89]. Proehl J. Adult Emergency Nursing Procedures: Peripheral Intravenous Cannulation. London: Jones \& Bartlett International, 2000; 196- 8.

[90]. Furest L. Technical Skills Lab on Empire 3 at KGH, in the Multi- media Learning Center in Bracken Library and on the Technical Skills. http://meds.queensu.com , 2004; 1 -7.

[91]. Trimble T. I.V rounds: Securing and removing peripheral I.V. Nursing, 2003; 33 (9): 26. 
[92]. Jarvis C. Physical Examination \& Health Assessment: Peripheral Vascular System and Lymphatic System. $4^{\text {th }}$ ed. Saunders Company, 2004; 534- 45.

[93]. Peterson K. Performing under pressure significantly decrease the number of times you must access an I.V. line saving time and reducing risks. Nursing, 2003; 33 (8):52-5.

[94]. Millam A. How to insert an intravenous. American Journal of Nursing, 2000; 79 (7): 1268-87, 1288-91, 1294-6.

[95]. Workman B. Peripheral intravenous management. Royal College of Nursing, 2002; 30 (9): 31-7.

[96]. Masoorli S, Infection control: how to prevent I.V. catheter contamination. Nursing, 2005; 35 (1): 60.

[97]. Peck N. Perfecting your intravenous therapy techniques. Nursing, 2003; 33(8): 43.

[98]. Franca L, Mrcna S. Peripheral intravenous cannulation in nursing performance predictors. Journal of Infusion Nursing, 2002; 25 (3): $189-95$.

[99]. Lenhardt R, Seybold T, Kimberger O. Local Warming and Insertion of Peripheral Venous Cannulas: Single Blinded Prospective Randomized Controlled Trial and Single Blinded 2004. http//: www.intravenous team.com. QJM journal, 2002; (325): 1038.

[100]. Masoorli S, Angeles T, Barbone M. Danger Points: how to prevent nerve injuries from vein puncture. Nursing, 2000; 30 (9): $35-40$.

[101]. Snively S. Therapy made incredibly easy, Saunders Company, 2001: peripheral venipuncture sites. Nursing, 2004; 34 (12): 30.

[102]. Hadaway L, Millam D. On the road to successful I.V starts. Nursing, 2006; 35 (5): 1-14.

[103]. Rosenthal K. Guarding against vascular site infection. Nursing Management, 2004; 35(11): 4 - 9.

[104]. Martin S. Intravenous therapy. I.V starts: improving your odds. Emergency Nursing World: 2005; 4 (2):70.

[105]. Smith N. Insert Intravenous Access Network: Your I.V: Voice on the Net. http://www.ivteamlist-subscribe@ivteam.plus, 2003 ; 1 4.

[106]. Cohen M, Early A, While K. Venipuncture and problem veins. American Journal of Nursing, 1999; 81(9): 1636-8.

[107]. Millam D. Tips for improving your venipuncture techniques. Nursing, 2005; 35(6):

[108]. Ellis J. Nowlis E, Bentz B. Modules for Basic Nursing Skills: Preparing and maintaining Intravenous Infusions, Applying Heat and Cold. $6^{\text {th }}$ ed. Philadelphia: Lippincott Company, 2003; 473- 609, 653- 75.

[109]. Mallert J, Dougherty L. The Royal Marsden Hospital Manual of Clinical Nursing Procedures: Vascular Access Devices Insertion and Management. $5^{\text {th }}$ ed. London: The Royal Marsden Hospital, 2000; 615- 21, 663- 72.

[110]. Walsh M. Clinical Nursing and Related Sciences $6^{\text {th }}$ ed. London: Balliere Tindall. Company, 2002; 95-109.

[111]. Moureau N. Focus on the Prevention of Vascular Access Device Complications: I.V. Complications Identification and Prevention. http://www.intravenoustherapy, 1999; 1-8.

[112]. Rosdahl C, Kowalski M. Textbook of Basic Nursing: Heat and Cold Application. $8^{\text {th }}$ ed. Philadelphia. Lippincott Williams \& Willing Company, 2003; 723- 7: 179-89.

[113]. Peck N. Perfecting your intravenous therapy techniques. Nursing, 2003; 13 (6): 32. 